\title{
Anti-CD45RA Antibody
}

National Cancer Institute

\section{Source}

National Cancer Institute. Anti-CD45RA Antibody. NCI Thesaurus. Code C158684.

Any antibody that recognizes receptor-type tyrosine-protein phosphatase $\mathrm{C}$ isoform CD45RA. 